\title{
Short-term mechanical stress inhibits osteoclastogenesis via suppression of DC-STAMP in RAW264.7 cells
}

\author{
SUMIKA KAMEYAMA $^{1,2}$, YOSHITAKA YOSHIMURA ${ }^{2}$, TAKESHI KAMEYAMA ${ }^{4}$, TAKASHI KIKUIRI ${ }^{3}$, \\ MINO MATSUNO $^{2}$, YOSHIAKI DEYAMA ${ }^{2}$, KUNIAKI SUZUKI ${ }^{2}$ and JUNICHIRO IIDA ${ }^{1}$ \\ Departments of ${ }^{1}$ Orthodontics, ${ }^{2}$ Molecular Cell Pharmacology and ${ }^{3}$ Pediatric Dentistry, Hokkaido University \\ Graduate School of Dental Medicine, Sapporo 060-8586; ${ }^{4}$ Division of Signaling in Cancer and \\ Immunology, Institute for Genetic Medicine, Hokkaido University, Sapporo 060-0815, Japan
}

Received September 26, 2012; Accepted November 16, 2012

DOI: $10.3892 /$ ijmm.2012.1220

\begin{abstract}
Mechanical stress is an important factor in bone homeostasis, which is maintained by a balance between bone resorption by osteoclasts and bone formation by osteoblasts. However, little is known about the effects of mechanical stress on osteoclast differentiation. In this study, we examined the effects of short-term mechanical stress on osteoclastogenesis by applying tensile force to RAW264.7 cells stimulated with receptor activator of nuclear factor- $\kappa B$ ligand (RANKL) using a Flexercell tension system. We counted the number of osteoclasts that were tartrate-resistant acid phosphatase (TRAP)-positive and multinucleated (two or more nuclei) with or without application of mechanical stress for $24 \mathrm{~h}$. Osteoclast number was lower after mechanical stress compared with no mechanical stress. Furthermore, mechanical stress for up to $24 \mathrm{~h}$ caused downregulation of osteoclast-specific gene expression and fusion-related molecule [dendritic cell specific transmembrane protein (DC-STAMP), osteoclast stimulatory transmembrane protein (OC-STAMP), E-cadherin, Integrin $\alpha \mathrm{V}$ and Integrin $\beta 3$ ] mRNA levels. Protein expression of DC-STAMP decreased with mechanical stress for $24 \mathrm{~h}$ compared to the control without mechanical stress, whereas the expression of E-cadherin, Integrin $\alpha \mathrm{V}$ and Integrin $\beta 3$ was slightly decreased. Nuclear factor of activated $\mathrm{T}$ cells $\mathrm{cl}$ (NFATc1) mRNA levels were decreased at $6 \mathrm{~h}$ and increased at 12 and $24 \mathrm{~h}$ compared with the control. The levels of NFATc2, NFATc3 mRNA did not change compared with the control group. By contrast, mechanical stress for $24 \mathrm{~h}$ significantly enhanced NFAT transcriptional activity compared with the control, despite a decrease in DC-STAMP mRNA and protein levels. These results suggest that short-term mechanical stress strongly inhibits osteoclastogenesis through the downregula-
\end{abstract}

Correspondence to: Dr Yoshitaka Yoshimura, Department of Molecular Cell Pharmacology, Hokkaido University Graduate School of Dental Medicine, Kita 13, Nishi 7, Kita-ku, Sapporo, Hokkaido 060-8586, Japan E-mail: yoshi@den.hokudai.ac.jp

Key words: mechanical stress, osteoclast, dendritic cell-specific transmembrane protein tion of DC-STAMP and other fusion-related molecules and that short-term mechanical stress induces a negative regulatory mechanism that cancels the enhancement of NFAT transcriptional activity.

\section{Introduction}

Osteoclasts are bone-resorbing, multinucleated giant cells differentiated from monocyte-lineage hematopoietic cells $(1,2)$. Disruption of bone resorption leads to sclerotic bone, as seen in osteopetrosis, whereas excessive resorption is central to the pathogenesis of osteoporosis, arthritis and periodontal disease. Thus, the elucidation of regulatory mechanisms involved in osteoclastogenesis is important to gain a deeper understanding of the health and disease of the skeletal system.

Osteoclast differentiation occurs in a series of events (3). First, precursors alter gene and protein expression to establish a fusion-competent status, enabling cell-cell recognition and attachment. Second, mononuclear preosteoclasts fuse together to become nonfunctional multinucleated osteoclasts that are polykaryons lacking ruffled borders. Finally, nonfunctional multinucleated osteoclasts are activated into functional bone resorbing osteoclasts by various factors.

Receptor activator of nuclear factor- $\kappa \mathrm{B}$ (RANK)-ligand (RANKL) is an essential factor for osteoclast differentiation (4). RANKL signaling induces the key transcription factor, nuclear factor of activated T cells c1 (NFATc1), which regulates a large number of the osteoclast-associated genes required for osteoclast differentiation and function $(5,6)$.

Mechanical stress is an important regulatory factor in bone homeostasis (7). Lack of stress causes bone loss and even osteoporosis in some cases, whereas stress overload leads to pathological bone modeling and remodeling (8). Previous studies investigated the responses of bone and bone cells to mechanical stresses, such as sheer stress (fluid flow) (9-11), compressive force (12-15), tensile force (16-18), hydrostatic pressure (19), microgravity (20), and others (21-23). Several reports have focused on the effect of mechanical stimulation on osteoblast-like cells, but the direct effect of mechanical stimulation on the behavior of osteoclast-like cells has only been investigated in a few studies. Therefore, we examined the effect of mechanical stress on osteoclast differentiation 
using a Flexercell tension system. We previously showed that mechanical stress (48-96 h) directly suppresses osteoclast differentiation and fusion $(24,25)$. However, the early phase effect of osteoclasts in response to direct mechanical stress has not been elucidated. Thus, this study investigated the effects of short-term mechanical stress (up to $24 \mathrm{~h}$ ) on osteoclast differentiation and fusion.

\section{Materials and methods}

Cell culture and osteoclast differentiation. Mouse monocyte/ macrophage RAW264.7 (RAW) cells (no. TIB-71 ${ }^{\mathrm{TM}}$; ATCC, Manassas, VA, USA) were used as osteoclast precursors. RAW cells were maintained in Dulbecco's modified Eagle's medium (DMEM) (Wako Pure Chemical, Osaka, Japan) supplemented with $10 \%$ fetal bovine serum (FBS) (Invitrogen, Carlsbad, CA, USA) and $66.7 \mu \mathrm{g} / \mathrm{ml}$ kanamycin sulfate (Meiji Seika, Japan) in a humidified atmosphere with $5 \% \mathrm{CO}_{2}$ at $37^{\circ} \mathrm{C}$. For osteoclast differentiation, RAW cells were plated at $9.0 \times 10^{4}$ cells/well in type I collagen-coated BioFlex Culture Plates (Flexcell International, Hillsborough, NC, USA) and were cultured with $\alpha$-minimum essential medium ( $\alpha$-MEM) (Wako Pure Chemical) supplemented with 10\% FBS, 2 mM L-alanyl-L-glutamine (Sigma-Aldrich, St. Louis, MO, USA), $284 \mu \mathrm{M}$ L-ascorbic acid 2-phosphate (Sigma-Aldrich) and $66.7 \mu \mathrm{g} / \mathrm{ml} \mathrm{kanamycin} \mathrm{sulfate}$ in the presence of $50 \mathrm{ng} / \mathrm{ml}$ RANKL (Oriental Yeast Co., Ltd., Tokyo, Japan).

Flexercell tension system. Mechanical stress was applied to RAW cells with the FX-3000 ${ }^{\mathrm{TM}}$ Flexercell Strain Unit (Flexcell International). RAW cells stimulated by RANKL were pre-cultured for three days and subjected to cyclical tensile force [ $10 \%$ elongation at 30 cycles/min $(0.5 \mathrm{~Hz})]$ for up to $24 \mathrm{~h}$. Control cells were plated on similar plates and kept in the same incubator, but were not subjected to strain.

Tartrate-resistant acid phosphatase (TRAP) staining. RAW cells were subjected to mechanical stress for $24 \mathrm{~h}$ and fixed with $10 \%$ neutral formalin. They were then washed with distilled water and stained with the TRAP staining solution (pH 5.0) supplemented with Fast Red Violet LB Salt (SigmaAldrich). TRAP-positive cells with more than two nuclei were counted under the microscope. The counted range was $1 \mathrm{~cm}^{2}$ dividing the circle in a fan-shape $(24,25)$.

RNA isolation and quantitative RT-PCR. RAW cells were subjected to mechanical stress for $0,6,12$ and $24 \mathrm{~h}$. Total RNA was extracted from osteoclastogenic cultures at different time points using the TRIzol reagent isolation kit (Invitrogen). First-strand cDNA was synthesized using ReverTra Ace- $\alpha$ FSK-101 (Toyobo, Osaka, Japan). We used specific primers for osteoclast-associated genes [TRAP, matrix metalloproteinase-9 (MMP-9), Cathepsin-K (Cath-K), calcitonin receptor (CTR), ATPase $\mathrm{H}^{+}$transporting vacuolar proton pump member I (ATP6i), chloride channel 7 (ClC7), dendritic cell-specific transmembrane protein (DC-STAMP), osteoclast stimulatory transmembrane protein (OC-STAMP), E-cadherin, Integrin $\alpha \mathrm{V}$, Integrin $\beta 3$, NFATc1, NFATc2 and NFATc3] as shown in Table I. Real-time quantitative PCR reactions were performed using the ABI PRISM 7300 sequence detection
Table I. Assey IDs of the primers used.

\begin{tabular}{lc}
\hline Gene & Assay ID \\
\hline TRAP & Mm00475698_m1 \\
MMP-9 & Mm00432271_m1 \\
Cath-K & Mm00484036_m1 \\
CTR & Mm00432271_m1 \\
ATP6i & Mm00469395_g1 \\
ClC7 & Mm00442400_m1 \\
DC-STAMP & Mm01168058_m1 \\
OC-STAMP & Mm00512445_m1 \\
E-cadherin & Mm01247357_m1 \\
Integrin $\alpha$ V & Mm00434506_m1 \\
Integrin $\beta 3$ & Mm00443980_m1 \\
NFATc1 & Mm00479445_m1 \\
NFATc2 & Mm00477776_m1 \\
NFATc3 & Mm01249194_m1 \\
GAPDH & Mm99999915_g1 \\
\hline
\end{tabular}

TRAP, tartrate-resistant acid phosphatase; MMP-9, matrix metalloproteinase-9; Cath-K, cathepsin-K; CTR, calcitonin receptor; ATP6i, ATPase $\mathrm{H}^{+}$transporting vacuolar proton pump member I; ClC7, chloride channel 7; DC-STAMP, dendritic cell-specific transmembrane protein; OC-STAMP, osteoclast stimulatory transmembrane protein; NFATc1, nuclear factor of activated T cells $\mathrm{cl}$.

system (Applied Biosystems, Foster City, CA, USA). Data were normalized to the expression of glyceraldehyde-3-phosphate dehydrogenase (GAPDH) for each sample and are shown as relative quantitation of target expression $\left(2^{-\Delta \Delta \mathrm{Ct}}\right.$ method) relative to control after normalization against GAPDH expression.

Western blot analysis. RAW cells were subjected to mechanical stress for $24 \mathrm{~h}$ and washed with ice-cold PBS and lysed in extraction buffer (50 mM Tris- $\mathrm{HCl}, \mathrm{pH} 7.5,150 \mathrm{mM} \mathrm{NaCl}$, $1 \mathrm{mM}$ EDTA, $1.0 \%$ Nonidet P-40 and protease inhibitors). Cell lysates were subjected to sodium dodecyl sulfate-polyacrylamide gel electrophoresis (SDS-PAGE) and western blotting. The following antibodies were used as primary antibodies: anti-DC-STAMP antibody (clone 1A; Millipore, Billerica, MA, USA), anti-E-cadherin antibody (24E10; Cell Signaling, Danvers, MA, USA), anti-Integrin $\alpha \mathrm{V}$ antibody (no. 3919-1; Cell Signaling), anti-Integrin $\beta 3$ antibody (no. 4702; Cell Signaling) and anti- $\beta$-actin antibody (AC-15; Sigma-Aldrich). Signals were detected and analyzed with a LAS1000 luminescent image analyzer (Fuji, Tokyo, Japan). Densitometric quantitation of western blot analyses was determined with the ImageJ software (http://rsbweb.nih.gov/ij/).

Luciferase reporter gene assay. RAW cells seeded on Flexercell 6-well plates were transiently cotransfected with luciferase reporter plasmids [100 ng each of pNF-AT-TA-Luc (Clontech Laboratories, Inc., Mountain View, CA, USA) and $10 \mathrm{ng}$ of pRL-SV40 (Toyo Ink, Tokyo, Japan) as an internal control] using FuGENE ${ }^{\circledR}$ HD (Promega, Madison, WI, USA) according 


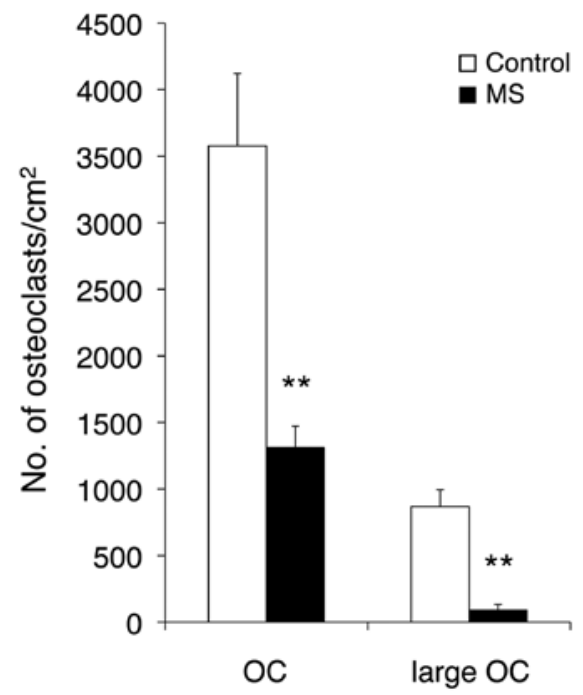

Figure 1. The number of osteoclasts decreases in response to mechanical stress. RAW cells $\left(9.0 \times 10^{4}\right.$ cells/well) were pre-cultured on Flexercell 6-well plates with RANKL ( $50 \mathrm{ng} / \mathrm{ml}$ ) for 3 days. Mechanical stress was applied for $24 \mathrm{~h}$, but was not applied to control cells. The number of TRAP-positive multinucleated cells with two or more nuclei (OC) and the number of large osteoclasts with eight or more nuclei (large $\mathrm{OC}$ ) are shown. Results are represented as the means $\pm \mathrm{SD}(\mathrm{n}=4) .{ }^{* *} \mathrm{P}<0.01$. MS, mechanical stress.
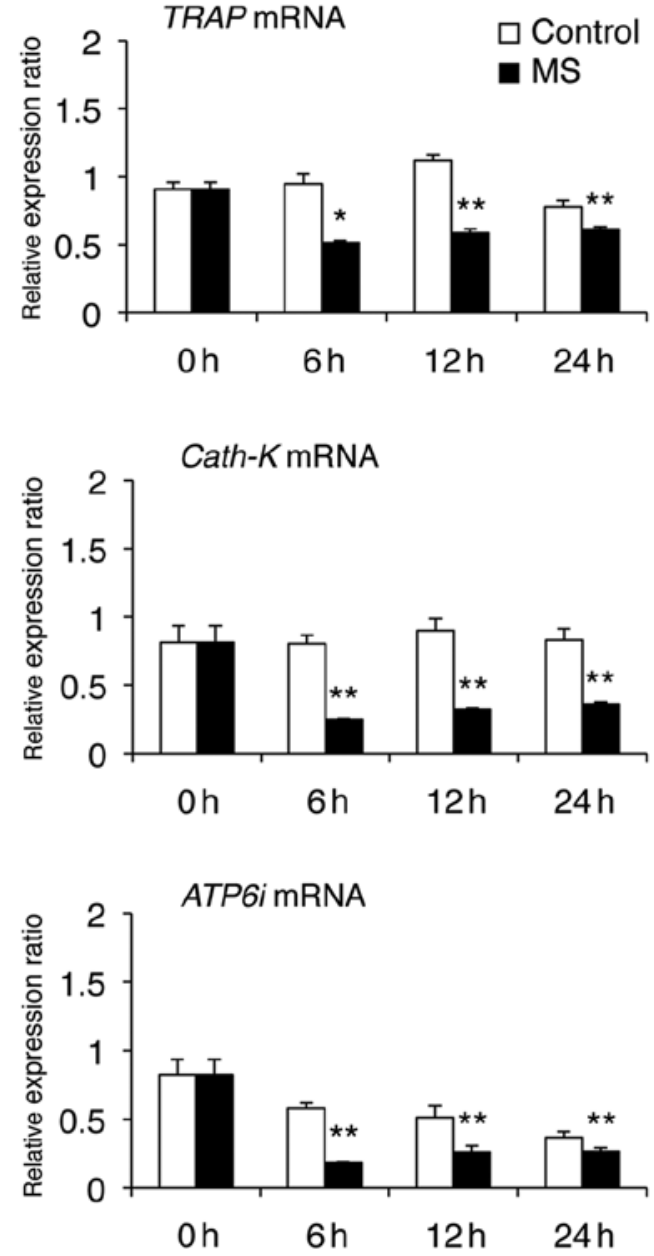

to manufacturer's protocol. Following transfection, RAW cells were subjected to mechanical stress for $24 \mathrm{~h}$, and the luciferase activity was performed with the Dual-Luciferase ${ }^{\circledR}$ Reporter Assay system (Promega).

Statistical analysis. All results are given as the means \pm SD. Comparisons between two groups were analyzed using the two-tailed unpaired Student's t-test. $\mathrm{P}<0.05$ was considered to indicate a statistically significant difference.

\section{Results}

The number of osteoclasts decreases in response to mechanical stress during osteoclast differentiation. To investigate the effect of short-term mechanical stress on osteoclast differentiation, we assessed the number of TRAP-positive multinucleated osteoclasts (Fig. 1). Mechanical stress was applied for $24 \mathrm{~h}$, while the control cells were grown in the same conditions, but without mechanical stress. Mechanical stress clearly inhibited osteoclastogenesis in RAW cells by $>40 \%$ compared with the control cells. Furthermore, the number of large osteoclasts with $>8$ nuclei was also significantly decreased by mechanical stress.
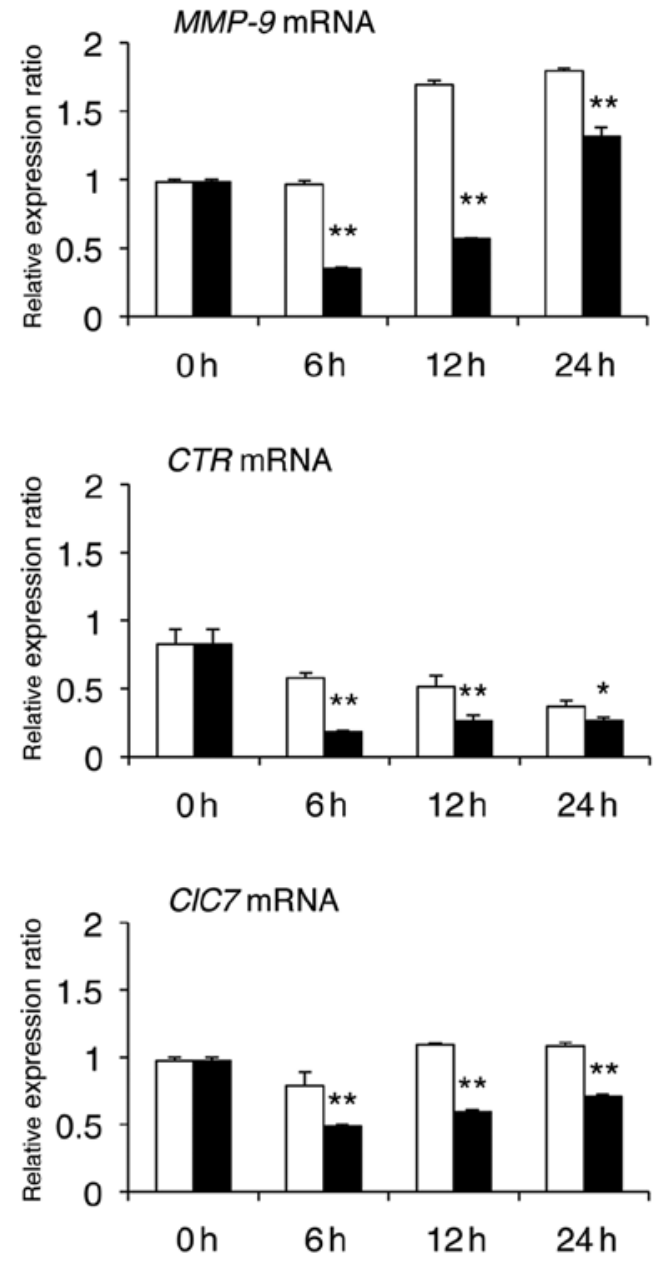

Figure 2. Effect of mechanical stress on the mRNA levels of osteoclast-specific genes. Tensile force was applied to RAW cells for 0,6 , 12 and 24 h, and the mRNA levels of osteoclast-specific genes were evaluated by quantitative RT-PCR. The control group, which was cultured for the same duration without mechanical stress, was defined as the standard. Real-time PCR analysis was performed with specific primers (Table I). Results are represented as the means $\pm \mathrm{SD}(\mathrm{n}=4) .{ }^{*} \mathrm{P}<0.01 ;{ }^{*} \mathrm{P}<0.05$. MS, mechanical stress. 

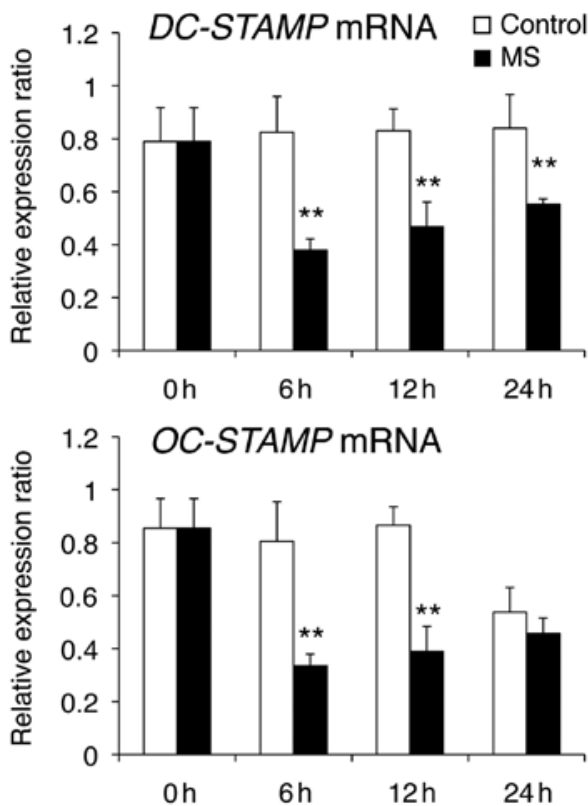

Figure 3. Effect of mechanical stress on the mRNA levels of DC-STAMP and OC-STAMP. The mRNA levels of DC-STAMP and OC-STAMP were evaluated by quantitative RT-PCR as described in Fig. 2. Results are represented as the means $\pm \mathrm{SD}(\mathrm{n}=4) .{ }^{* *} \mathrm{P}<0.01 ;$. MS, mechanical stress.
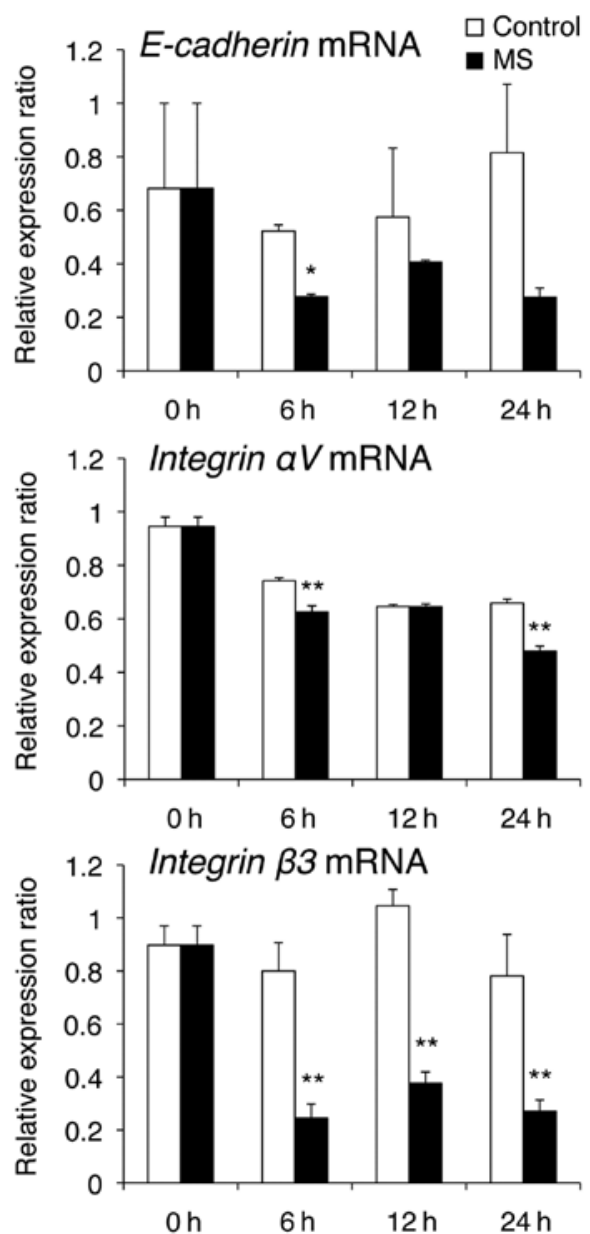

Figure 4. Effect of mechanical stress on the mRNA levels of E-cadherin, Integrin $\alpha \mathrm{V}$ and Integrin $\beta 3$. The mRNA levels of E-cadherin, Integrin $\alpha \mathrm{V}$ and Integrin $\beta 3$ were evaluated by quantitative RT-PCR as described in Fig. 2. Results are represented as the means $\pm S D(n=4) .{ }^{* *} \mathrm{P}<0.01$; ${ }^{*} \mathrm{P}<0.05$. MS, mechanical stress.
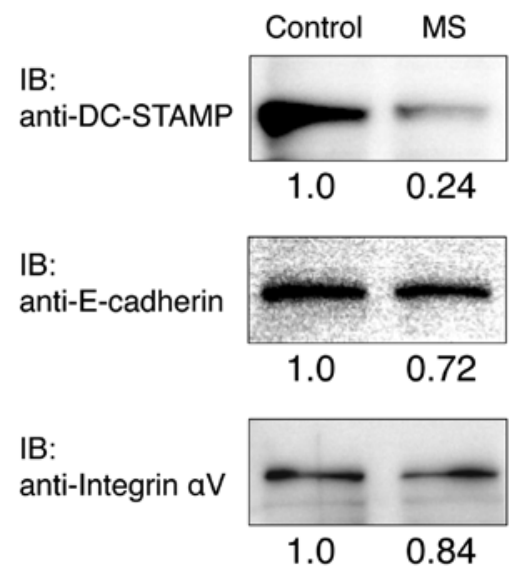

IB: anti-Integrin $\beta 3$

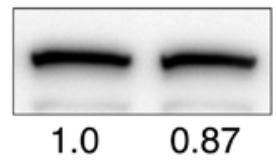

IB:

anti- $\beta$-actin

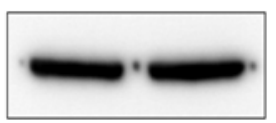

Figure 5. Mechanical stress decreases the protein levels of DC-STAMP, whereas there was little decrease in the protein levels of E-cadherin, Integrin $\alpha \mathrm{V}$ and Integrin $\beta 3$. RAW cells were cultured with or without mechanical stress for $24 \mathrm{~h}$, and the protein levels of Integrin $\alpha \mathrm{V}$, Integrin $\beta 3$, E-cadherin and DC-STAMP were determined by western blot analysis. $\beta$-actin was analyzed as an internal control. Each value represents the densitometry of a band divided by the densitometry for the corresponding $\beta$-actin. MS, mechanical stress. Results are shown from one of three independent experiments.

Expression of osteoclast-associated genes. We next examined the effect of mechanical stress $(6,12$ or $24 \mathrm{~h})$ on the mRNA levels of osteoclast-specific genes (TRAP, CTR, MMP-9, Cath-K, ClC7 and ATP6i) and fusion-related molecules (DC-STAMP, OC-STAMP, E-cadherin, Integrin $\alpha \mathrm{V}$ and Integrin $\beta 3$ ) that are required for osteoclast differentiation and bone resorption. Real-time PCR analysis revealed that mechanical stress caused downregulation of mRNA levels of osteoclast-specific genes (Fig. 2), DC-STAMP (Fig. 3) and Integrin $\beta 3$ (Fig. 4). OC-STAMP mRNA levels were markedly reduced at 6 and $12 \mathrm{~h}$ compared with those in control cells (Fig. 3). E-cadherin mRNA levels were markedly reduced at $6 \mathrm{~h}$ compared with those in the control cells, while Integrin $\alpha \mathrm{V}$ mRNA levels were decreased at 6 and $24 \mathrm{~h}$, compared with those in control cells (Fig. 4).

Protein levels of DC-STAMP, E-cadherin, Integrin $\alpha V$ and Integrin $\beta 3$. RAW cells were cultured with or without mechanical stress for $24 \mathrm{~h}$, and the protein expression levels of Integrin $\alpha \mathrm{V}$, Integrin $\beta 3$, E-cadherin and DC-STAMP were determined by western blot analysis (Fig. 5). The protein expression level of DC-STAMP was clearly reduced compared with the control after culturing for $24 \mathrm{~h}$. Integrin $\alpha \mathrm{V}$, Integrin $\beta 3$ and E-cadherin protein expressions were slightly reduced compared with the control.

Gene expression and transcriptional activity of NFAT. The transcription factor NFATc1 plays an essential role in osteoclast differentiation and regulates a number of osteoclast-associated 

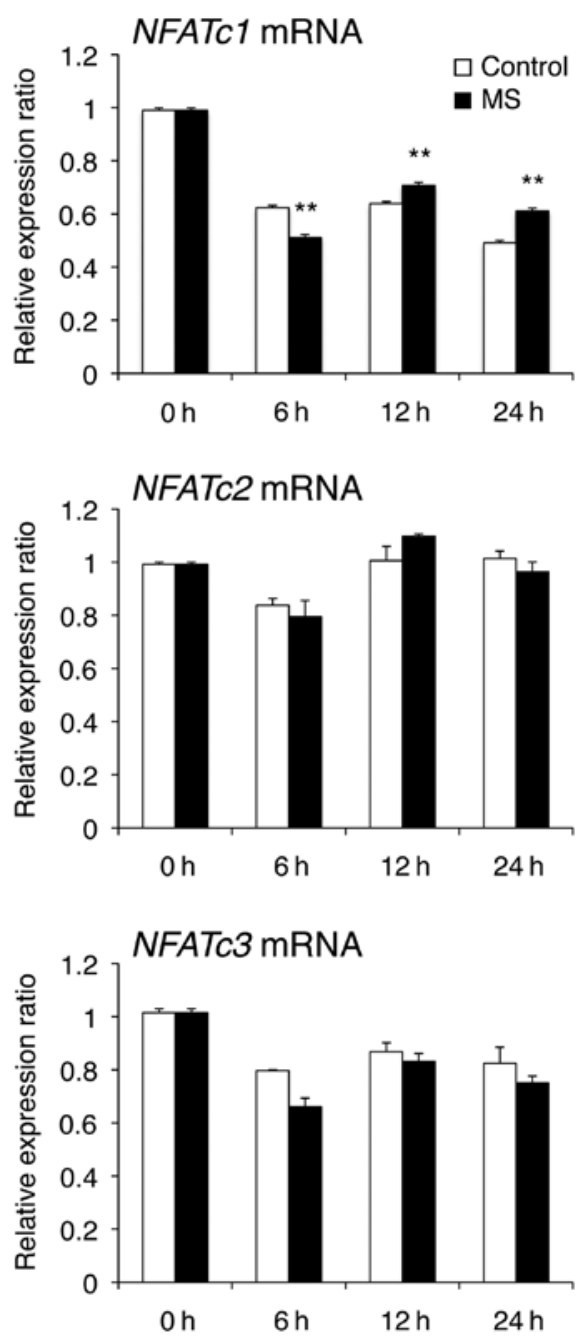

Figure 6. Effect of mechanical stress on the mRNA levels of the NFATc family. The mRNA levels of the NFATc family were evaluated by quantitative RT-PCR as described in Fig. 2. Results are represented as the means \pm SD $(n=4) .{ }^{* *} \mathrm{P}<0.01$. MS, mechanical stress.

genes, such as TRAP, CTR, MMP-9, Cath-K, ClC7, ATP6i, DC-STAMP, OC-STAMP and Integrin $\beta 3$. To explore the relationship between mechanical stress and NFATc1, we investigated the effect of mechanical stress on mRNA levels and transcriptional activity of NFAT. NFATc1 mRNA levels were decreased when compared at $6 \mathrm{~h}$ and increased at 12 and $24 \mathrm{~h}$ compared with those in control cells (Fig. 6). However, NFATc2 and NFATc3 mRNA levels were unchanged when compared with those in control cells. Furthermore, mechanical stress markedly enhanced NFAT transcriptional activity at $24 \mathrm{~h}$ compared with the control (Fig. 7).

\section{Discussion}

This study demonstrated that tensile force inhibits osteoclast differentiation and fusion by suppressing several osteoclastassociated genes in the early phase, which is consistent with results from previous reports $(24,25)$. Furthermore, mRNA and protein levels of DC-STAMP, which is essential for cellcell fusion of osteoclasts, decreased in response to short-term mechanical stress.

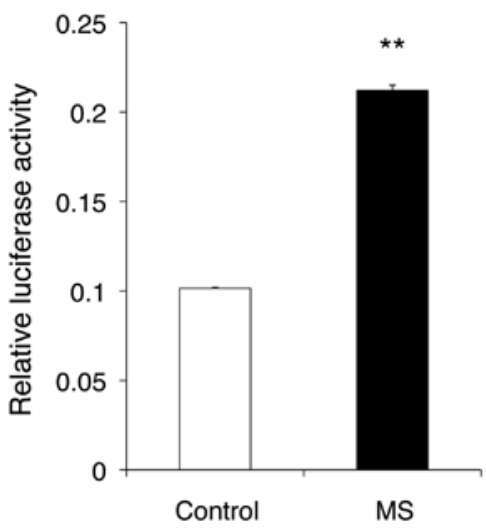

Figure 7. Mechanical stress for $24 \mathrm{~h}$ enhances NFAT transcriptional activity when compared with that in control cells. RAW cells were seeded on Flexercell 6-well plates and were transiently cotransfected with luciferase reporter plasmids (100 ng each of pNF-AT-TA-Luc and $10 \mathrm{ng}$ of pRL-SV40 as an internal control). After transfection, RAW cells were subjected to mechanical stress for $24 \mathrm{~h}$, and the luciferase activity was measured with the Dual-Luciferase Reporter Assay system. Results are represented as the means $\pm \operatorname{SD}(n=4) .{ }^{* *} \mathrm{P}<0.01$. MS, mechanical stress.

Cell-cell fusion is a critical event for the development of multinucleated osteoclasts, which occurs in a multi-step process that involves cell-cell and cell-matrix interactions, cell spreading and membrane-membrane fusion $(3,26)$. To date, several molecules have been identified as fusion-related elements in osteoclasts. DC-STAMP was originally identified in dendritic cells as an interleukin (IL)-4 inducible protein consisting of seven transmembrane domains (27). DC-STAMP is also found in macrophages and osteoclasts and is essential for the multinucleation of osteoclasts in the presence of RANKL and macrophage colony-stimulating factor (M-CSF) (28). Studies with mice that are genetically deficient for DC-STAMP suggest a critical role for osteoclast precursor (OCP) fusion, since these mice have few multinucleated TRAP-positive osteoclasts and have increased bone mineral density (28-31). Conversely, experiments in DC-STAMP transgenic mice revealed accelerated bone resorption and a concomitant decrease in bone mass (32). NFATc1 binds to the promoter regions of DC-STAMP in osteoclasts and directly induces the expression of DC-STAMP (33). Thus, the NFATc1DC-STAMP signaling axis plays a key role in the osteoclast multinucleation process that is essential for efficient bone resorption. A previous study showed that RANKL induces OC-STAMP, which is a multipass transmembrane protein that promotes the formation of multinucleated osteoclasts (34). Cell-cell fusion in osteoclasts is modulated cooperatively by OC-STAMP and DC-STAMP, both of which are induced by the RANKL-NFATc1 axis (35). In this study, the mRNA levels of DC-STAMP and OC-STAMP decreased in response to mechanical stress along with a decrease in the number of osteoclasts. Furthermore, the protein levels of DC-STAMP were also clearly reduced in response to mechanical stress compared with those in control cells. These results suggest that mechanical stress suppresses osteoclastogenesis, possibly through the inhibition of cell-cell fusion via the downregulation of DC-STAMP and OC-STAMP.

E-cadherin and Integrin $\alpha \mathrm{V} \beta 3$ are also related to osteoclast fusion. Cadherins are calcium-dependent adhesion molecules 
that mediate cell-cell adhesion. Mbalaviele et al (36) reported that blocking E-cadherin suppresses macrophage fusion in vitro, supporting a key role for E-cadherin in the attachment of precursors prior to fusion. When precursors arrive at bone, integrin-mediated attachment is required for differentiation. Integrin $\alpha \mathrm{V} \beta 3$ is the most important integrin for proliferation of osteoclast precursor cells to form multinuclear cells and for subsequent bone resorption (37). In this study, the mRNA and protein levels of E-cadherin, Integrin $\alpha \mathrm{V}$ and Integrin $\beta 3$ decreased in response to mechanical stress compared with the control. These results suggest that mechanical stress may suppress expressions of E-cadherin, Integrin $\alpha \mathrm{V}$ and Integrin $\beta 3$.

We found that there is a discrepancy between mRNA expression of NFATc1-mediated genes and NFAT transcriptional activity; mechanical stress suppressed the mRNA expression of DC-STAMP and other osteoclast-associated genes that are transcriptionally regulated by NFATc1, whereas NFATreporter assay revealed that NFAT transcriptional activity was enhanced by mechanical stress. The following may be possible causes of this discrepancy; the first cause is that some negative transcriptional regulator of NFATs may be induced by mechanical stress and this factor suppresses osteoclastassociated genes. This possibility seems to be low as several osteoclast-associated genes that have different promoters are downregulated in response to mechanical stress. The other is that mechanical stress may induce epigenetic changes in osteoclast-associated genes. Indeed, it has been reported that epigenetic mechanisms including histone acetylation and methylation are important for osteoclast differentiation (38). Furthermore, demethylation of H3K27me3 in the Nfatc1 gene locus by Jmjd3 plays a critical role in RANKL-induced osteoclast differentiation (39), and JMJD5 negatively regulates osteoclastogenesis as a post-translational co-repressor for NFATc1 (40). It is possible that there is an association between mechanical stress and the epigenetic regulation. Although further investigations are required to clarify this discrepancy, our results suggest that mechanical stress induces a negative regulatory mechanism that cancels the enhancement of NFAT transcriptional activity.

During osteoclastogenesis, NFATc1 is a crucial transcriptional factor and autoregulates its own promoter (38). In this study, NFATc1 mRNA was decreased at $6 \mathrm{~h}$, compared with control, whereas NFATc1 mRNA was increased at 12 and $24 \mathrm{~h}$. Although these mRNA changes have statistical significance, these slight changes may not explain the NFAT transcriptional activation in response to mechanical stress. These data suggest that NFAT transcriptional activation in response to mechanical stress was caused by NFAT functional change, not by induction of NFAT mRNA.

Tension stress promotes bone formation. Distraction osteogenesis (DO) is the process of generating new bone in a gap between two bone segments in response to the application of graduated tensile stress across the bone gap (41-43). The application of DO offers new possibilities for the treatment of orofacial anomalies, such as mandibular widening in transverse direction or lengthening of the vertical and horizontal mandibular ramus. Widening of the maxilla by means of DO is the most common application. Similarly, orthodontic tooth movement necessitates bone resorption at the pressure side with concomitant bone formation at the tension side of periodontal ligament. The present study helps to elucidate the mechanism of bone formation with tension stress and may have therapeutic implications.

In conclusion, this study demonstrated that short-term mechanical stress strongly inhibits osteoclast differentiation and fusion through the downregulation of DC-STAMP and other fusion-related molecules. Moreover, it induces a negative regulatory mechanism that cancels the enhancement of NFAT transcriptional activity.

\section{Acknowledgements}

We are grateful to Dr K. Shibata for the technical advice and support. This study was supported in part by the Japan Society for the Promotion of Science Grants-in-Aid for Scientific Research (C) nos. 22592274 to Y.Y., 24659906 to T.K. and 24593071 to M.M.

\section{References}

1. Teitelbaum SL and Ross FP: Genetic regulation of osteoclast development and function. Nat Rev Genet 4: 638-649, 2003.

2. Boyle WJ, Simonet WS and Lacey DL: Osteoclast differentiation and activation. Nature 423: 337-342, 2003.

3. Helming L and Gordon S: Molecular mediators of macrophage fusion. Trends Cell Biol 19: 514-522, 2009.

4. Suda T, Takahashi N, Udagawa N, Jimi E, Gillespie MT and Martin TJ: Modulation of osteoclast differentiation and function by the new members of the tumor necrosis factor receptor and ligand families. Endocr Rev 20: 345-357, 1999.

5. Negishi-Koga T and Takayanagi $\mathrm{H}: \mathrm{Ca}^{2+}$-NFATc1 signaling is an essential axis of osteoclast differentiation. Immunol Rev 231: 241-256, 2009.

6. Nakashima $\mathrm{T}$ and Takayanagi H: New regulation mechanisms of osteoclast differentiation. Ann NY Acad Sci 1240: E13-E18, 2011.

7. Thompson WR, Rubin CT and Rubin J: Mechanical regulation of signaling pathways in bone. Gene 503: 179-193, 2012.

8. Al Nazer R, Lanovaz J, Kawalilak C, Johnston JD and Kontulainen S: Direct in vivo strain measurements in human bone-a systematic literature review. J Biomech 45: 27-40, 2012.

9. Mehrotra M, Saegusa M, Wadhwa S, Voznesensky O, Peterson D and Pilbeam C: Fluid flow induces Rankl expression in primary murine calvarial osteoblasts. J Cell Biochem 98: 1271-1283, 2006.

10. Tan SD, de Vries TJ, Kuijpers-Jagtman AM, Semeins CM, Everts V and Klein-Nulend J: Osteocytes subjected to fluid flow inhibit osteoclast formation and bone resorption. Bone 41: 745-751, 2007.

11. Kulkarni RN, Bakker AD, Everts $\mathrm{V}$ and Klein-Nulend J: Mechanical loading prevents the stimulating effect of IL-1 $\beta$ on osteocyte-modulated osteoclastogenesis. Biochem Biophys Res Commun 420: 11-16, 2012.

12. Ichimiya H, Takahashi T, Ariyoshi W, Takano H, Matayoshi T and Nishihara T: Compressive mechanical stress promotes osteoclast formation through RANKL expression on synovial cells. Oral Surg Oral Med Oral Pathol Oral Radiol Endod 103: 334-341, 2007.

13. Zhang F, Wang CL, Koyama Y, Mitsui N, Shionome C, Sanuki R, Suzuki N, Mayahara K, Shimizu N and Maeno M: Compressive force stimulates the gene expression of IL-17s and their receptors in MC3T3-E1 cells. Connect Tissue Res 51: 359-369, 2010.

14. Cho ES, Lee KS, Son YO, Jang YS, Lee SY, Kwak SY, Yang YM, Park SM and Lee JC: Compressive mechanical force augments osteoclastogenesis by bone marrow macrophages through activation of c-Fms-mediated signaling. J Cell Biochem 111: 1260-1269, 2010

15. Kaneuji T, Ariyoshi W, Okinaga T, Toshinaga A, Takahashi T and Nishihara T: Mechanisms involved in regulation of osteoclastic differentiation by mechanical stress-loaded osteoblasts. Biochem Biophys Res Commun 408: 103-109, 2011. 
16. Rubin J, Murphy TC, Fan X, Goldschmidt M and Taylor WR: Activation of extracellular signal-regulated kinase is involved in mechanical strain inhibition of RANKL expression in bone stromal cells. J Bone Miner Res 17: 1452-1460, 2002.

17. Koike M, Shimokawa H, Kanno Z, Ohya K and Soma K: Effects of mechanical strain on proliferation and differentiation of bone marrow stromal cell line ST2. J Bone Miner Metab 23: 219-225, 2005.

18. Kanzaki H, Chiba M, Sato A, Miyagawa A, Arai K, Nukatsuka S and Mitani H: Cyclical tensile force on periodontal ligament cells inhibits osteoclastogenesis through OPG induction. J Dent Res 85: 457-462, 2006.

19. Rubin J, Biskobing D, Fan X, Rubin C, McLeod K and Taylor WR: Pressure regulates osteoclast formation and MCSF expression in marrow culture. J Cell Physiol 170: 81-87, 1997.

20. Makihira S, Kawahara Y, Yuge L, Mine Y and Nikawa H: Impact of the microgravity environment in a 3-dimensional clinostat on osteoblast- and osteoclast-like cells. Cell Biol Int 32: 1176-1181, 2008.

21. Kadow-Romacker A, Hoffmann JE, Duda G, Wildemann B and Schmidmaier G: Effect of mechanical stimulation on osteoblastand osteoclast-like cells in vitro. Cells Tissues Organs 190: 61-68, 2009.

22. Kurata K, Uemura T, Nemoto A, Tateishi T, Murakami T, Higaki $\mathrm{H}$, Miura $\mathrm{H}$ and Iwamoto $\mathrm{Y}$ : Mechanical strain effect on bone-resorbing activity and messenger RNA expressions of marker enzymes in isolated osteoclast culture. J Bone Miner Res 16: 722-730, 2001

23. Yan YX, Gong YW, Guo Y, Lv Q, Guo C, Zhuang Y, Zhang Y, Li R and Zhang XZ: Mechanical strain regulates osteoblast proliferation through Integrin-mediated ERK activation. PLoS One 7: e35709, 2012.

24. Suzuki N, Yoshimura Y, Deyama Y, Suzuki K and Kitagawa Y: Mechanical stress directly suppresses osteoclast differentiation in RAW264.7 cells. Int J Mol Med 21: 291-296, 2008.

25. Shibata K, Yoshimura Y, Kikuiri T, Hasegawa T, Taniguchi Y, Deyama Y, Suzuki K and Iida J: Effect of the release from mechanical stress on osteoclastogenesis in RAW264.7 cells. Int J Mol Med 28: 73-79, 2011.

26. Oursler MJ: Recent advances in understanding the mechanisms of osteoclast precursor fusion. J Cell Biochem 110: 1058-1062, 2010.

27. Hartgers FC, Vissers JL, Looman MW, van Zoelen C, Huffine C, Figdor CG and Adema GJ: DC-STAMP, a novel multimembranespanning molecule preferentially expressed by dendritic cells. Eur J Immunol 30: 3585-3590, 2000.

28. Yagi M, Miyamoto T, Sawatani Y, Iwamoto K, Hosogane N, Fujita N, Morita K, Ninomiya K, Suzuki T, Miyamoto K, Oike Y, Takeya M, Toyama Y and Suda T: DC-STAMP is essential for cell-cell fusion in osteoclasts and foreign body giant cells. J Exp Med 202: 345-351, 2005.

29. Kukita T, Wada N, Kukita A, Kakimoto T, Sandra F, Toh K, Nagata K, Iijima T, Horiuchi M, Matsusaki H, Hieshima K, Yoshie $\mathrm{O}$ and Nomiyama H: RANKL-induced DC-STAMP is essential for osteoclastogenesis. J Exp Med 200: 941-946, 2004

30. Yagi M, Miyamoto T, Toyama Y and Suda T: Role of DC-STAMP in cellular fusion of osteoclasts and macrophage giant cells. J Bone Miner Metab 24: 355-358, 2006.
31. Yagi M, Ninomiya K, Fujita N, Suzuki T, Iwasaki R, Morita K, Hosogane N, Matsuo K, Toyama Y, Suda T and Miyamoto T: Induction of DC-STAMP by alternative activation and downstream signaling mechanisms. J Bone Miner Res 22: 992-1001, 2007.

32. Iwasaki R, Ninomiya K, Miyamoto K, Suzuki T, Sato Y, Kawana H, Nakagawa T, Suda T and Miyamoto T: Cell fusion in osteoclasts plays a critical role in controlling bone mass and osteoblastic activity. Biochem Biophys Res Commun 377: 899-904, 2008.

33. Kim K, Lee SH, Ha Kim J, Choi Y and Kim N: NFATc1 induces osteoclast fusion via up-regulation of Atp6v0d2 and the dendritic cell-specific transmembrane protein (DC-STAMP). Mol Endocrinol 22: 176-185, 2008

34. Yang M, Birnbaum MJ, MacKay CA, Mason-Savas A, Thompson B and Odgren PR: Osteoclast stimulatory transmembrane protein (OC-STAMP), a novel protein induced by RANKL that promotes osteoclast differentiation. J Cell Physiol 215: 497-505, 2008

35. Miyamoto H, Suzuki T, Miyauchi Y, Iwasaki R, Kobayashi T, Sato Y, Miyamoto K, Hoshi H, Hashimoto K, Yoshida S, Hao W, Mori T, Kanagawa H, Katsuyama E, Fujie A, Morioka H, Matsumoto M, Chiba K, Takeya M, Toyama Y and Miyamoto T: Osteoclast stimulatory transmembrane protein and dendritic cell-specific transmembrane protein cooperatively modulate cell-cell fusion to form osteoclasts and foreign body giant cells J Bone Miner Res 27: 1289-1297, 2012.

36. Mbalaviele G, Chen H, Boyce BF, Mundy GR and Yoneda T: The role of cadherin in the generation of multinucleated osteoclasts from mononuclear precursors in murine marrow. J Clin Invest 95: 2757-2765, 1995 .

37. Miyamoto T, Arai F, Ohneda O, Takagi K, Anderson DM and Suda T: An adherent condition is required for formation of multinuclear osteoclasts in the presence of macrophage colonystimulating factor and receptor activator of nuclear factor kappa B ligand. Blood 96: 4335-4343, 2000.

38. Asagiri M, Sato K, Usami T, Ochi S, Nishina H, Yoshida H, Morita I, Wagner EF, Mak TW, Serfling E and Takayanagi H: Autoamplification of NFATc1 expression determines its essential role in bone homeostasis. J Exp Med 202: 1261-1269, 2005.

39. Yasui T, Hirose J, Tsutsumi S, Nakamura K, Aburatani H and Tanaka S: Epigenetic regulation of osteoclast differentiation: possible involvement of Jmjd3 in the histone demethylation of Nfatc1. J Bone Miner Res 26: 2665-2671, 2011.

40. Youn MY, Yokoyama A, Fujiyama-Nakamura S, Ohtake F, Minehata K, Yasuda H, Suzuki T, Kato S and Imai Y: JMJD5, a Jumonji C (JmjC) domain-containing protein, negatively regulates osteoclastogenesis by facilitating NFATc1 protein degradation. J Biol Chem 287: 12994-13004, 2012.

41. Ilizarov GA: The tension-stress effect on the genesis and growth of tissues. Part I. The influence of stability of fixation and softtissue preservation. Clin Orthop Relat Res 238: 249-281, 1989.

42. Ilizarov GA: The tension-stress effect on the genesis and growth of tissues: Part II. The influence of the rate and frequency of distraction. Clin Orthop Relat Res 239: 263-285, 1989.

43. Ilizarov GA: Clinical application of the tension-stress effect for limb lengthening. Clin Orthop Relat Res 250: 8-26, 1990. 